\title{
La naturaleza como percepción cultural. Montes y selvas en el Nuevo Reino de Granada, siglo XVIII
}

\author{
Edgardo Pérez Morales \\ Universidad Andina Simón Bolívar, Ecuador \\ epm8302@hotmail.com
}

\begin{abstract}
Resumen $^{1}$
El trabajo es una aproximación al mundo de las percepciones culturales sobre los principales entornos selváticos del Nuevo Reino de Granada durante el siglo XVIII, basada fundamentalmente en la consulta sistemática de fuentes primarias manuscritas y publicadas y apoyada en algunos aportes fundamentales de la perspectiva cultural de la historia ambiental y de la historia cultural del período de la Ilustración. En lo fundamental, se presentan las ideas, valoraciones, tensiones conflictivas y usos técnicos que se generaron desde los ámbitos perceptivos de los pobladores urbanos, las autoridades virreinales, algunos grupos indígenas y los hombres ilustrados. La noción de desierto, la sensibilidad del miedo o la categoría de "barbarie" se destacan entre los componentes principales de la percepción cultural de la época, estrechamente ligada a herencias europeas judeocristianas.
\end{abstract}

Palabras clave: MONTES, SELVAS, NUEVO REINO DE GRANADA, SIGLO XVIII, HISTORIA AMBIENTAL.

\begin{abstract}
This paper is an approach to the world of cultural perceptions on the Nuevo Reino de Granada main sylvan environments during the XVIIIth. Century, based mainly on the systematic search of manuscript and published primary sources, and supported on some fundamental contributions of the environmental history cultural perspective and the Enlightenment period cultural history. Basically, the ideas, valuations, conflictive tensions and technical uses that were generated from the perceptive fields of urban inhabitants, viceroyalty authorities, some indigenous groups and enlightened men are presented. The notion of desert, the sensibility of fear or the category of "savagery" are pointed out among

\footnotetext{
${ }^{1}$ El presente artículo está basado en un capítulo de mi trabajo de grado para optar al título de Historiador en la Universidad Nacional de Colombia, sede Medellín, titulado "Espacios y vida material en el Nuevo Reino de Granada durante el siglo XVIII" y desarrollado entre los años 2004 y 2005 bajo la dirección del profesor Orián Jiménez. Una versión preliminar fue presentada al II Simposio Internacional Interdisciplinario de Colonialistas de las Américas, Bogotá, Colonial American Studies Organization-Pontificia Universidad Javeriana, agosto 8-11 de 2005. Agradezco los comentarios de los profesores Óscar Almario, Luis Miguel Córdoba, Juan David Montoya y de los compañeros del grupo de investigación al que pertenezco.
} 
the period cultural perception main elements, tightly linked to Judeo-Christian European legacies.

Key words: WOODS, FOREST, NATURE CULTURAL PERCEPTION, URBAN INHABITANTS, INDIGENOUS, VICEROYALTY AUTHORITIES, ENLIGHTENED MEN.

Si bien los fenómenos y espacios naturales han constituido desde antaño una preocupación particular dentro de la reflexión social, tal como lo muestra David Arnold con su tesis sobre el paradigma ambientalista, ha sido desde hace dos o tres décadas que explícitamente y con mayor rigor se ha asimilado la naturaleza como un problema histórico, específicamente por las corrientes conocidas como historia ambiental o ecohistoria, pero también dentro de otras perspectivas de indagación, como la historia de la vida material y las nuevas tendencias de la geografía histórica $^{2}$. Precisamente, tales enfoques han producido algunos de sus aportes más importantes a través del estudio de los "mundos coloniales". Son ampliamente conocidas las contribuciones sobre las consecuencias ecológicas del cruce de "fronteras biológicas" producido por el encuentro entre Europa, América y África desde fines del siglo XV, e igualmente se empiezan a difundir nuevas perspectivas al respecto. Por otro lado, la experiencia colonial de la India es otro mojón importantísimo en la historia e historiografía de la naturaleza y sus relaciones con el hombre y en ella, al igual que en el caso del mundo americano, también son evidentes las conexiones entre el imperialismo y la explotación y modificación del entorno y la relación estrecha entre los sustratos culturales y simbólicos de los pueblos y su relación con la percepción del medio ambiente ${ }^{3}$. En relación directa con lo anterior, es necesario resaltar uno de los aportes más importantes de estas corrientes investigativas: el reconocimiento de que la mayoría de las fuentes con que cuentan los historiadores para estudiar situaciones de colonialismo están íntimamente ligadas a predisposiciones valorativas de los dominadores y en general a las retóricas del imperialismo y la dominación, aun en aquellos casos en que parecen describir inocentemente realidades tangibles. Lo anterior debe invitar

\footnotetext{
${ }^{2}$ Sobre el paradigma ambientalista y el desarrollo de la historia ambiental, véase David Arnold, La naturaleza como problema histórico. El medio, la cultura y la expansión de Europa (1996; reimpresión, México: Fondo de Cultura Económica, 2001).

${ }^{3}$ Alfred W. Crosby, Imperialismo ecológico. La expansión biológica de Europa, 900-1900 (1986; reimpresión, Barcelona: Crítica, 1999); Guillermo Castro Herrera, "Naturaleza, sociedad e historia en América Latina", en Ecología politica. Naturaleza, sociedad y utopía, comp. Héctor Alimonda (Buenos Aires: Consejo Latinoamericano de Ciencias Sociales, 2002), 83-99; Silvia Meléndez Dobles, "La historia ambiental: aportes interdisciplinarios y balance crítico desde América Latina", en Cuadernos digitales (Costa Rica), 7, núm. 19, (2002), revista en línea (Costa Rica: Universidad de Costa Rica, 2002). Obtenido de la red mundial el 6 de septiembre de 2006, 12:30 horas. http://historia.fcs.ucr.ac.cr/cuadernos/c19-his.pdf.
} 
sobre todo a la crítica de fuentes, pero también a la exploración de otro tipo de retóricas presentes en la documentación que dejaron las experiencias del pasado.

Durante el siglo XVIII, gran cantidad de espacios geográficos del Nuevo Reino de Granada estaban cubiertos por espesa vegetación arbórea, como lo eran las selvas tropicales de las tierras bajas o los montes de las cordilleras andinas. La presencia de tales conglomerados forestales obedecía no solo a los procesos ecológicos de cada región, sino también, en muchos casos, a que su continuidad era clave para las comunidades indígenas, a su despoblamiento total o a que habían quedado al margen de la colonización y deforestación europeas. Pero dichos espacios no constituían una unidad en lo que a las valoraciones y la percepción cultural se refiere, y es esto, precisamente, lo que se indicará en las siguientes páginas. No es mi intención proponer una idea unívoca de lo que interpreto como percepción cultural, pero sí quiero hacer explícito que con tal categoría creo conveniente englobar las ideas "cifradas" según herencias simbólicas y las sensibilidades específicas del hombre como individuo o como parte de cierta comunidad ${ }^{4}$. Tales presencias son a menudo descritas con detalle en las fuentes de época y corresponde al investigador vincularlas con corrientes históricas más generales y significados profundos.

El presente artículo es un ejercicio en esa dirección organizado en cinco secciones. La primera presenta la relación entre el proyecto civilizatorio colonial y los recursos forestales; la segunda muestra cómo las ideas generadas por este proyecto y la tradición centenaria de los hombres de tradición hispánica generaron una percepción del monte y de la selva mediada por la idea del desierto y la sensibilidad del miedo, lo cual, como se expone en la tercera sección, se acompañó del correlato de la barbarie y la gentilidad para calificar a los pobladores permanentes de estos espacios. En la cuarta sección se exploran las relaciones de apropiación y percepción de los entornos selváticos por parte de los indígenas, mostrando que estas hacían parte de sus realidades técnicas y rituales. Finalmente, el artículo explora el modo como la perspectiva cultural de la Ilustración produjo

\footnotetext{
${ }^{4}$ El problema de la percepción cultural es trascendental no únicamente con respecto a las sociedades y espacios estudiados, sino también en lo tocante a las estrategias de estudio que se han desarrollado a través del tiempo. Arnold, La naturaleza y Peter J. Bowler, Historia Fontana de las ciencias ambientales (1992; reimpresión, México: Fondo de Cultura Económica, 1998). Se admite aquí que la percepción es siempre cultural y que, teniendo en cuenta una propuesta del sociólogo Norbert Elias, es una interesante combinación de las sensibilidades y las formas de saber: "La manera como los miembros individuales de un grupo experimentan todo lo que afecta a sus sentidos, el significado que atribuyen a sus percepciones sensoriales, depende de la forma estándar del saber $-\mathrm{y}$, con este, también de la capacidad de formular conceptos- que la sociedad a la que pertenecen ha alcanzado a largo de su evolución", "Compromiso y distanciamiento" [1956-1977/1978], en Compromiso y distanciamiento. Ensayos de sociología del conocimiento (Barcelona: Península, 1990), 13.
} 
un giro valorativo entre ciertos sectores de la sociedad colonial con respecto a la naturaleza, en el cual montes y selvas se presentaron como espacios cuya percepción debía secularizarse y que podían ser explotados racionalmente como receptáculos de recursos útiles.

\section{Civilización y recursos forestales}

En el contexto de lo que actualmente es Colombia y Ecuador, y seguramente en muchas otras regiones del mundo hispánico, el uso de las nociones de monte y selva se diferenciaba según las áreas geográficas y las relaciones entre ellas y los hombres que las habitaban, transitaban o explotaban, de manera que se convertían en convenciones culturales variables más que en rótulos homogéneos que hicieran referencia a significantes específicos. Así por ejemplo, el término "selva" no parece haber sido tan usado, aunque es posible que se empleara cuando la frondosidad e intrincación de los árboles, "malezas" y matas asombraran o atemorizaban contundentemente al hombre de tradición hispánica y urbana, por lo que aparece en fuentes que se refieren al Pacífico (llanuras aluviales y vertientes cordilleranas de las gobernaciones de Popayán y Chocó) o a las tierras amazónicas; con todo, la noción aparece también en aquellos casos en los que era más común recurrir al término "monte", que a su vez hacía referencia tanto a elevaciones terrestres como a espacios cubiertos de árboles (monte alto) o de malezas (monte bajo $)^{5}$. Montaña era una palabra que también se usaba con un significado similar.

Aunque percibidos de manera diferente, en muchos casos existió una peculiar relación entre esos espacios naturales y los centros urbanos coloniales. Si se tiene en cuenta la hipótesis del historiador Felipe Fernández-Armesto, quien ha reformulado recientemente el uso tradicional de la palabra civilización para referirse a las relaciones que se establecen entre los seres humanos y el resto de la naturaleza, en las cuales la transformación y remodelación del entorno ambiental por parte del hombre y con funciones específicas tienen un papel central ${ }^{6}$, podrá deducirse que los proyectos ibéricos de conquista y colonización del Nuevo

\footnotetext{
${ }^{5}$ Diccionario de la Lengua castellana en el que se explica el verdadero sentido de las voces, su naturaleza y calidad, con las phrases o modos de hablar, los proverbios o refranes, y otras cosas convenientes al uso de la lengua, 3 t. (Madrid: Real Academia Española, 1726-1739; edición facsímil bajo el título Diccionario de Autoridades, Madrid: Gredos, 2002), vol. II, t. 4: 601. Sobre la diferencia entre las nociones de montaña y monte en la región Caribe y el altiplano central (cundiboyacense), puede consultarse Marta Herrera Ángel, Ordenar para controlar. Ordenamiento espacial y control político en las llanuras del Caribe y en los Andes centrales neogranadinos. Siglo XVIII (Bogotá: Academia Colombiana de Historia; Instituto Colombiano de Antropología e Historia, 2002), 49-52.

6 Felipe Fernández-Armesto, Civilizaciones. La lucha del hombre por controlar la naturaleza (2000; reimpresión, Madrid: Taurus, 2002), 15-22.
} 
Mundo, en los que la vida urbana jugó un papel fundamental, recibieron una herencia de la historia del mundo occidental y particularmente del Imperio Romano y su modelo de vida urbana, arraigado con fuerza particular en el mundo mediterráneo. Tal modelo otorgó un legado en el cual los espacios arbóreos representaban la antítesis de la ciudad, por lo que la deforestación conllevaba tanto la carga de las necesidades citadinas (construcción, combustibles, etc.) como la carga de la expansión de un proyecto de civilización. Los nexos son más evidentes cuando se recuerda que la doctrina del cristianismo reemplazó al Imperio asimilando antiguos legados, por lo cual en donde incursionaba el culto cristiano la tradición de vida urbana hacía otro tanto, siempre a costa de los árboles y con la legitimidad de un dios que había entregado el mundo natural sin reparos al hombre, tal como se percibía desde el judaísmo. Con todo, fue a partir del siglo XII, con la gran expansión del cristianismo, que Europa experimentó un proyecto para domeñar el bosque, fundado en las necesidades de la vida urbana, la arquitectura, la agricultura, la ganadería, el comercio y la religiosidad ${ }^{7}$.

Es por ello que las ciudades y las villas, como parte de sus necesidades fundamentales, pero también como parte de un proyecto civilizador, expandían su radio de control ecológico y dominación cultural reemplazando lentamente los montes adyacentes por campos de cultivo y praderías pecuarias, lo cual se apoyaba en las retóricas de las "jurisdicciones" y los "términos". Así por ejemplo, la escasa presencia de montes en las jurisdicciones de Santafé y Tunja le ofrecía a la población blanca, y probablemente a los indígenas hispanizados y a los mestizos, un paisaje con el cual podían estar culturalmente a gusto, pues eran los cultivos, hatos y centros urbanos y semiurbanos los que dominaban la campiña ${ }^{8}$. Sin embargo, había presencia de "montañas" en las cordilleras, que eran usufructuadas para la cacería y la explotación forestal".

Si bien pueden considerarse como civilización las formas y técnicas con las que los hombres usan y modifican su entorno natural, es necesario anotar que las colectividades no siempre están de acuerdo en cómo deben llevarse a cabo tales procesos. Un caso particular es el del valle de Aburrá, en donde, recién creada la villa de Medellín, se desató un enfrentamiento por la explotación de los montes aledaños al igual que por los cañaverales y pastizales. En tal caso, eran las nociones del "bien común" e "intereses particulares" los fundamentos que se debatían para establecer con claridad si tales recursos podían ser controlados por

\footnotetext{
${ }^{7}$ Ibídem, 172-181; Fernand Braudel, Civilización material, economía y capitalismo, siglos $X V$-XVIII, t. 1, Las estructuras de lo cotidiano: lo posible y lo imposible (1967; reimpresión, Madrid: Alianza, 1984), 420-421; Simon Schama, Landscape and Memory (1995; reimpresión, Nueva York: Vintage Books, 1996), 142.

${ }^{8}$ Herrera, Ordenar para controlar, 51.

${ }^{9}$ Como sucedía, por ejemplo, en Facatativá y Sibaté. Archivo General de la Nación -en adelante AGN-(Bogotá), Policía, t. 9, número de orden 2, fols. 389r-389v.
} 
algunos vecinos o usufructuados por todos los pobladores sin inconveniente alguno $^{10}$. Otro tanto sucedía en la ciudad portuaria de Guayaquil, en la Audiencia de Quito, en donde se presentaban problemas por el control político y fiscal de las selvas cercanas. Aunque hay mucho que comentar al respecto, bastará con anotar que Guayaquil expandía su dominio civilizatorio sin eliminar en su totalidad las selvas cercanas, sino explotándolas según principios políticos específicos y procurando que los recursos, aunque estaban bajo su posesión, no desaparecieran totalmente. La función principal de esta estrategia era mantener el astillero en funcionamiento, y el astillero, a su vez, era importante no únicamente para Guayaquil, sino para otras latitudes, al ser un modelo de actividad técnica que podía repetirse "a escala", como sucedía en Tumaco e Iscuandé, también sobre la costa pacífica, en la gobernación de Popayán ${ }^{11}$.

\section{El ideario de "desierto" y las sensibilidades del miedo}

Bien se trate de un océano, un río, una selva o un bosque, los espacios geográficos son siempre interpretados, valorados y considerados como tales por medio de razones e ideas culturales. Aun aquellos paisajes que suponemos más libres de alguna cultura, evaluados con detalle pueden aparecer como su producto. Así considerado, un paisaje puede ser, antes que naturaleza, el precipitado de construcciones culturales de la imaginación proyectadas en los componentes del entorno, a manera de metáforas que pueden hacerse más reales que sus referentes y que tienen la capacidad de sobrevivir por largo tiempo en la memoria ${ }^{12}$.

Como se ha visto ya, la expansión de las ciudades a costa de espacios forestales tenía que ver tanto con las necesidades de los grupos sociales urbanos como con una visión particular de lo que debía ser el espacio civilizado. A lo anterior hay que agregar que a dichos fenómenos los han acompañado percepciones centenarias de las selvas y los montes, que subsistían en el siglo XVIII entre la sociedad dominante de tradición hispánica. Tales percepciones son, en lo fundamental, la autoridad del hombre para domeñar y explotar a su antojo la naturaleza; el ideario de lo selvático o boscoso como "desierto"; la valoración por parte de las sociedades urbanas y campesinas del monte o la selva como espacios terroríficos, estructurados y habitados de forma insospechada, por lo que no puede evitarse el miedo como experiencia sensible, una vez se entra allí; finalmente, y como

\footnotetext{
${ }^{10}$ Luis Miguel Córdoba Ochoa, De la quietud a la felicidad. La villa de Medellín y los procuradores del cabildo entre 1675 y 1785 (Bogotá: Instituto Colombiano de Cultura Hispánica, 1998), 86-95.

${ }^{11}$ Esta hipótesis y sus importantes implicaciones están siendo analizadas por el profesor Óscar Almario en su investigación de tesis doctoral; comunicación personal, Medellín, marzo de 2005

${ }^{12}$ Schama, Landscape, 3-19. Para el caso de específico de los espacios forestales, ibídem, Word, parte 1: 21-242.
} 
consecuencia de todo lo anterior, la idea de que los habitantes permanentes de los espacios arbóreos, excepto pocos casos, son bárbaros, incivilizados, forajidos y malignos, y la consiguiente proyección retórica al respecto.

En cuanto a la autoridad del hombre sobre la naturaleza, es indudable la raíz judeocristiana de tal valoración, pues en dicha tradición es dios quien entrega al hombre el mundo entero para su señorío ${ }^{13}$. Así, las luchas políticas por la explotación de recursos naturales en el Nuevo Reino de Granada y la expansión de los elementos paisajísticos urbanos y rurales contaban con un componente religioso común a la cultura hispánica.

Como quedó dicho, el cristianismo heredó también la tradición urbana, opuesta a lo boscoso, y junto con el legado de la tradición hebraica, especialmente después del siglo IV, insertó los elementos del desierto judío como experiencia espiritual en lugares como islas y monasterios, $\mathrm{y}$ en las regiones septentrionales, paradójicamente, en un espacio natural distinto, como lo era el bosque. Así, debido a una herencia milenaria en la que se han entrelazado las realidades materiales y espirituales recurriendo en múltiples direcciones a lo geográfico y lo simbólico, lo imaginario y lo económico, lo social y lo ideológico, el bosque, y en el Nuevo Mundo los montes y las selvas, fueron equiparables al desierto ${ }^{14}$. No es extraño pues que en las fuentes del siglo XVIII que mencionan frondosos espacios arbóreos se recurriera con insistencia a la noción de desierto, y que tal categoría fuera utilizada en algunos mapas de la época. De esta manera, cuando en 1781 Pedro Biturro Pérez escribió su relación sobre los caminos de Hervé, Nare y Palagua, en la provincia de Antioquia, a solicitud del gobernador Cayetano Buelta Lorenzana, manifestó los inconvenientes del carácter selvático de algunos tramos de estos caminos y recurrió a la noción de desierto para especificar la soledad y la falta de sustento para el hombre y sus animales de carga, más no la ausencia de vegetación. Biturro escribió que después del páramo de Hervé en el río Salado,

[...] cuando hay la desgracia de que se entre invierno pasando tan repetidas veces este río, es preciso hacer estación en una de sus ensenadas, en la que coge su avenida, expuestos todos a perecer de hambre, si no da treguas, y también las mulas por no haber pastos en estas medianías, sin que se pueda remediar, ni ser socorrido por parte alguna en aquel desierto profundo,

\footnotetext{
${ }^{13}$ Con todo, y aunque tal idea se usó para legitimar la explotación y con mayor razón para erradicar las creencias "paganas" que protegían árboles y animales de una destrucción irracional, ya desde tiempos medievales hubo sectores del cristianismo que se pronunciaron a favor de la naturaleza. Arnold, La naturaleza, 122-123. Lo anterior, es posible, estaría ligado a la idea de un hombre "pastor" que, como dios, está por fuera de la naturaleza pero ha recibido de él el encargo de cuidarla. Bowler, Historia Fontana, 10, 47.

${ }^{14}$ Jacques Le Goff. "El desierto y el bosque en el occidente medieval", en Lo maravilloso y lo cotidiano en el Occidente medieval (Barcelona: Gedisa, 1986), 30.
} 
cuyas cordilleras parece están vecinas al cielo, y sin márgenes el río por la represión de éstas ${ }^{15}$.

Igualmente, en 1804 el barón de Carondelet, presidente de la Audiencia de Quito, se refería a la zona que mediaba entre la gobernación de Popayán y la provincia de Antioquia como un área de "desiertos fragosos como dilatados" por los cuales era sumamente difícil conducir los efectos del comercio ${ }^{16}$, mientras que más de medio siglo antes el jesuita Joseph Gumilla, a pesar de destacar la nutrida vida social de los habitantes del Orinoco y la riqueza de sus selvas, calificaba dicha región como una zona de "desiertas arboledas"17.

En lo tocante al temor y el miedo que generaban los montes y las selvas, nuevamente vuelve a aparecer la experiencia de la cristiandad por cuanto su expansión se enfrentó a bosques habitados por tradiciones paganas, espacios poblados por demonios, hadas, elfos, duendes, árboles vivos y al acecho, entre otros "horrores no exorcizados" 18 . Así, a las ideas de los hombres que habitaban los bosques de la Europa septentrional se fue sumando la interpretación de las mismas por los evangelizadores cristianos, y, a su vez, tal compendio cultural fue asumido, en algunos de sus aspectos, por los primeros y los posteriores observadores del Nuevo Mundo, desde fines del siglo XV en las conquistas ibéricas y desde principios del siglo XVII por los colonizadores ingleses ${ }^{19}$. De tal manera, en el caso del miedo cuentan no solo las tradiciones europeas sino también los relatos de los cronistas de Indias, pues sus obras, fuera de su "formato" europeo, presentaban elementos propios de la experiencia del Nuevo Mundo ${ }^{20}$. En realidad, aunque es obvio que aún se necesita una investigación específica al respecto, para el siglo XVIII pervivían con más fuerza los relatos de los cronistas, no obstante que todavía se considerara que algunos parajes estaban habitados por seres malignos de la imaginación europea, como sucedía en una cumbre atravesada por el camino de

\footnotetext{
15 Archivo Histórico de Antioquia -en adelante AHA- (Medellín), Caminos, t. 71, doc. 1971, fol. 31r. Énfasis agregado. Sobre los caminos en la provincia de Antioquia entre el siglo XVI y mediados del siglo XIX puede consultarse Orián Jiménez Meneses, Edgardo Pérez Morales y Felipe Gutiérrez Flórez, eds., Caminos, rutas y técnicas: huellas espaciales y estructuras sociales en Antioquia (Medellín: Universidad Nacional de Colombia, 2005).

${ }_{16}$ AHA (Medellín), Caminos, t. 3252, doc. 10, fol. 166v. Para otro ejemplo, véase AGN (Bogotá), Mejoras Materiales, t. 6, fols. 403-418.

${ }^{17}$ Joseph Gumilla, El Orinoco ilustrado. Historia natural, civil, y geográfica de este gran río (1741; reimpresión, Bogotá: ABC, 1955).

${ }^{18}$ Fernández-Armesto, Civilizaciones, 152.

${ }^{19}$ Arnold, La naturaleza, 125.

${ }^{20}$ David A. Brading, Orbe indiano. De la monarquía católica a la república criolla, 14921867 (1991; reimpresión, México: Fondo de Cultura Económica, 2003).
} 
Hervé, "en donde se halla un plan de media cuadra, que llaman el Patio de las Brujas, porque siempre está sin hierva, es como barrido y tierra muy fuerte"21.

Ahora bien, las fuentes manuscritas son más reveladoras en otro sentido; el miedo que nacía en los hombres de tradición hispánica -es decir, blancos peninsulares y criollos, mestizos y en ciertas ocasiones indígenas reducidos a pueblos y algunos esclavos- cuando incursionaban en los montes y las selvas para efectos de exploraciones, apertura de caminos, búsqueda de minas, explotaciones forestales, cacería o persecución de esclavos cimarrones o indios "bravos", se derivaba fundamentalmente del alejamiento de los espacios en que reinaba su propio régimen de vida material y en los que conocían las estrategias adecuadas para asegurar el cubrimiento básico de las necesidades de alimentación (física y espiritual), morada y vestido ${ }^{22}$. En efecto, una noción como "selvatiquez" hacía referencia a la "tosquedad, rusticidad, y falta de urbanidad, y policía" ${ }^{23}$. Lo anterior implicaba, igualmente, las penurias e incomodidades generadas por el clima y las estadías continuas al aire libre, y la inquietud fundada por la proximidad con las "fieras" que podían atacar en el momento menos pensado. De aquí que sea posible sugerir que el miedo se generaba no por desconocimiento, sino, todo lo contrario, por un conocimiento algo detallado de lo que eventualmente podía suceder en los montes.

En aquellas ocasiones en que era la apertura de caminos la empresa que obligaba a los vecinos de alguna ciudad o villa a internarse en los montes y encontrar rutas adecuadas para la comunicación y el comercio, la tarea misma se veía coma una lucha contra la naturaleza, pues las trochas y los caminos debían arrebatarle espacios al dominio arbóreo, espacios que podían, si se descuidaban, quedar "cerrados de montes y embarazados con los árboles que los vientos han derribado haciéndolos mucho más intransitables" ${ }^{24}$. Después de que tramos considerables de trochas quedaban como laceraciones antrópicas en los montes y a medida que más se alejaban los exploradores de sus centros de origen, era necesario asegurar la forma de abastecerse de víveres, como el maíz, pues tal era el sustento básico en dichas correrías, si bien los personajes más "baquianos" en la vida por los montes podían acceder a otros comestibles vegetales y presas de caza. Igualmente, se hacía indispensable la construcción de pequeñas trojes y moradas para el almacenamiento de herramientas y víveres y la habitación de los hombres. Así, cuando José de Montoya, vecino del valle de Urrao, y su yerno José de Vargas

${ }^{21}$ AHA (Medellín), Caminos, t. 71, doc. 1971, fol. 30r.

${ }^{22}$ De ahí el hecho de que la persecución de los "bárbaros" e "incivilizados" en espacios que también pueden calificarse así sea presentada a menudo, tanto en la historia de Europa como en la historia de América, como una situación épica en la que se recalcan el esfuerzo y el sacrifico de los cristianos en las empresas de salvación.

${ }^{23}$ Diccionario de la Lengua castellana, vol. III, t. 6: 71.

${ }^{24}$ AGN (Bogotá), Mejoras Materiales, t. 17, fol. $984 \mathrm{v}$. 
atravesaron la espesura de los montes que separaban la provincias de Antioquia y Chocó comisionados por el gobernador Buelta Lorenzana para el descubrimiento de un camino, aseguraron una primera estación en las cabeceras del río Nendó, en donde "se armaron un tambo bastante grande, y una rocería para sembrar maíz a fin de tener abrigo, y víveres para proseguir en el descubrimiento de dicho camino" 25 . Desde tal paraje se abastecía el frente de trabajo de la trocha, y cuando hubo necesidad, ya en el río Arquía, construyeron otro rancho.

Las experiencias de climas variados y cambiantes en lugares "desérticos" en los que se hacía difícil asegurarse una morada y sustento alimentario adecuados podían ser particularmente extremas, y en algunos casos eran magnificadas. Biturro Pérez, en la citada relación, mencionaba que en el páramo de Hervé:

El frío es excesivo en conformidad de que el agua que se trasnocha en el jarro amanece cuajada, al beberlo a cualquiera hora del día el primero, y segundo trago, se siente fría, y los siguientes entran como hirviendo, por lo que entume la frialdad. Si uno para ocho días en este paraje, por el beneficio de las mulas, que allí quedan rendidas las que no se han quedado muertas, o estropeadas, observa se le afloja la dentadura con el frío. Si se pone al sol en paraje defendido del viento, le levanta ampolla en breve rato. Si se pone a la sombra donde corra viento, como con una lanza, lo penetra el frío: De noche es necesario tener agua a mano, porque asaltan unas sequías tan repentinas, que no se pueden aguantar el tiempo en que se reza el credo, con un calor intenso que parece tener fuego en el pecho, lo que se atempera con el agua ${ }^{26}$.

Por su parte, Manuel Arciniégas, vecino de Santafé, declaraba que en los montes de Hervé las lluvias podían hacer crecer los afluentes, como el Guarinó, con lo que los viajeros "han de esperar a que baje por lo que antecedentemente algunos mercaderes se sujetaron a comerse las mulas, perros, y aun las petacas" ${ }^{27}$. Lo anterior recuerda las peripecias de los conquistadores y seguramente las traía también a la memoria de algunos hombres del siglo XVIII, bien fuera porque las habían oído o porque conocían las crónicas escritas. Don Ignacio Echeverri, alcalde de San José de la Marinilla, también informó de las calamidades climáticas que hicieron temer lo peor cuando azotaron a los vecinos que se habían trasladado a los montes del páramo de Guatapé, donde:

[...] para el reparo de la noche, no había otro abrigo techado que el de unos lienzos que llamamos sobre toldos, y éstos las muchas lluvias que hicieron

\footnotetext{
${ }^{25}$ Ibídem, fol. 989v.

${ }^{26}$ AHA (Medellín), Caminos, t. 71, doc. 1971, fol. 30r.

${ }^{27}$ Ibídem, doc. 1973, fols. 446v-448r, 460r.
} 
los calaban, y aun muchos por no caber en aquel pequeño resguardo quedaban a la inclemencia de las injurias del tiempo, por lo que a prevención de los referidos riesgos (que antes de salir no fueron tan premeditados como se experimentaron) llevé en mi compañía al maestro don Isidoro Gómez presbítero para sí, ocurriese la necesidad de confesión $[\ldots]^{28}$.

Todas estas circunstancias afectaban la salud de los hombres no acostumbrados a los montes y las selvas, por lo que la gente pensaba que tales espacios podían amenazar profundamente el bienestar físico y hasta la vida misma, como se acaba de ver. En efecto, don Juan Pablo Pérez de Rublas reconocía que la construcción de caminos que atravesaran las selvas del occidente de la provincia de Antioquia debía estar en manos de los indios nativos del área, pues:

\begin{abstract}
Estos individuos habituados a aquellas montañas sufren las incomodidades que ellas ofrecen sin decadencia alguna en su salud, por cuyo motivo sólo ellos podrán sin interrupción concurrir a la apertura de este camino todo el tiempo que haya de durar y que de contrario no se podría conseguir con otros peones que acostumbrados a vivir en población miran con horror, y tedio un largo trabajo, obligados a residir por muchos meses en una montaña $[\ldots]^{29}$.
\end{abstract}

Los animales depredadores y venenosos aportaban otro tanto para generar la sensibilidad del miedo entre los hombres que se adentraban en los montes, pues si bien muchos de ellos eran sumamente versados en el conocimiento de los animales comestibles, como "venados", saínos o paujiles, al igual que en técnicas efectivas para su cacería $a^{30}$, algunas especies eran consideradas "fieras" y "animales ponzoñosos" que podían atacar a los seres humanos durante los trajines del día o en el descuido de algún descanso nocturno ${ }^{31}$. Tal era la idea que se tenía de "tigres", "leones", algunas especies de cerdos de monte, "víboras" y culebras venenosas ${ }^{32}$.

\footnotetext{
${ }^{28}$ Ibídem, doc. 1969, fols. 6v, 7r.

${ }^{29}$ AGN (Bogotá), Mejoras Materiales, t. 17, fol. 821v. Énfasis agregado.

${ }^{30}$ La gran variedad de especies "montaraces" conocidas por los hombres del siglo XVIII puede constatarse en AHA (Medellín), Estadística y Censo, t. 343, doc. 6538, y Basilio Vicente de Oviedo, Cualidades y riquezas del Nuevo Reino de Granada (Bogotá: Biblioteca de Historia Nacional, 1930), 52-69.

${ }^{31}$ AHA (Medellín), Caminos, t. 71, doc. 1969, fol. 7v, ibídem, doc. 1980, fols. 9r-10r.

${ }^{32}$ El cura Oviedo escribió que "Los que aquí llaman leones, pero no son como los de África, ni tienen tanto cuerpo ni grandeza, son como un gran mastín o lebrel, y tienen competentes garras y dientes", Basilio Vicente de Oviedo, Cualidades, 55.
} 


\section{La retórica de la barbarie}

A consecuencia de todo lo anterior, los hombres de tradición hispánica, usualmente blancos y mestizos vinculados radicalmente con un régimen de vida material en el que los espacios urbanos eran fundamentales, condenaban a los habitantes permanentes de espacios selváticos como bárbaros, incivilizados, forajidos $\mathrm{y}$ malignos. En este punto, nuevamente, se mezclan las tradiciones de la vieja Europa con las experiencias del Nuevo Mundo. En efecto, en la imaginación europea los espacios boscosos no eran únicamente habitáculos de maldad, paganismo e incivilidad, sino que constituían también regiones particulares de refugio para forajidos criminales y políticos, mientras que en el mundo hispanoamericano las selvas y montes podían llegar a ser el espacio de esperanza al que solían marcharse los indígenas, huyendo de la masacre, la esclavización y la enfermedad, y en el que los esclavos asentaban sus centros de refugio y resistencia. Ahora bien, en el caso europeo, y más específicamente en el inglés, la caracterización de habitantes tradicionales del bosque como forajidos provenía muchas veces de la novedad de valoraciones e imposiciones reales sobre tales espacios, y del consiguiente choque cultural y político ${ }^{33}$. Pero más que analizar situaciones similares para el caso del Nuevo Reino de Granada, quiero retener la idea de que durante el siglo XVIII se recurrió con frecuencia a las nociones de barbarie y gentilidad para calificar a los hombres que habitaban los montes y las selvas, particularmente a los indígenas.

Es así como Francisco Silvestre, en sus Apuntes Reservados, manifestaba que en el virreinato "Queda una vasta extensión de terreno llena de bosques y fieras en que todavía subsisten sin reducirse algunos indios". Sobre tales indígenas, Silvestre señalaba que en el Darién tenían sojuzgada la provincia "los indios gentiles", quienes "suelen hacer incursiones en las haciendas" y en la costa del Sinú, en que dejan siempre señales funestas de su "bárbara crueldad". Acerca de los indios de Chocó escribió que "aunque reducidos a pueblo, se mantienen tan gentiles como antes, por falta de doctrina". El funcionario proponía que en las reducciones a poblados debía tratarse de "españolizar" a todos los indios y asimilarlos a la población libre de tributo personal ${ }^{34}$. Por su parte, don Juan Pablo Pérez de Rublas, quien como el anterior burócrata citado llegó a ocupar la gobernación de la provincia de Antioquia, manifestaba a fines del siglo XVIII que los indios de las selvas de Chocó "vivían abandonados en aquellas montañas a la más crasa barbarie, olvidan no sólo de las máximas de nuestra Religión sino también de toda

\footnotetext{
${ }^{33}$ Schama, Landscape, 142-153.

34 "Apuntes reservados particulares y generales del estado actual del Virreinato de Santafé de Bogotá [...] Por Don Francisco Silvestre [1789]", en Relaciones e informes de los gobernantes de la Nueva Granada, Germán Colmenares (Bogotá: Biblioteca Banco Popular, 1989), 2: 102-108.
} 
sociedad en común [...]"35. Pero estas condenas no deben ocultar el hecho de que los indígenas que habitaban las selvas tenían sus propias "máximas" para la vida en dichos entornos, como lo eran la ritualidad y el conocimiento práctico.

\section{Ritualidad y técnicas: la apropiación de la selva entre los indígenas}

En su artículo "The Use of Wild Plants in Tropical South America", contribución a la importante obra editada por Julian H. Steward, el antropólogo Claude LéviStrauss, hace más de cincuenta años, presentó una valiosa síntesis de las principales pautas ecológicas y culturales que han existido entre los indígenas de las selvas tropicales suramericanas para efectos del conocimiento y uso de las plantas que allí crecen ${ }^{36}$. El debate introductorio del artículo gira en torno al hecho de que resulta difícil distinguir con certeza entre plantas silvestres y cultivadas, pues existen etapas intermedias entre el uso de plantas de naturaleza propiamente silvestre o su uso tras lo que sería un verdadero proceso de cultivo. Igualmente, Lévi-Strauss planteó que los procedimientos culturales de explotación de cada comunidad, más que estardeterminados por la oferta ecológica de sus entornos, se originan de procesos históricos de apropiación y habilidad, y que tanto la recolección como el cultivo, y las etapas intermedias, requieren técnicas altamente refinadas $^{37}$. Pero no solo el mundo de la técnica entre los indígenas de las selvas tropicales es altamente refinado, el uso de los recursos de espacios forestales ha estado también íntimamente ligado a las pautas mentales de conocimiento y a la ritualidad que a la vez rodean y sostienen la vida de las comunidades indígenas ${ }^{38}$. En efecto, múltiples trabajos históricos y etnográficos han dado cuenta de lo anterior, por lo que se puede asegurar que entre muchas comunidades indígenas la selva es un espacio en el que la incursión y la estadía de los hombres obedece a motivos particulares que requieren acciones precisas, a menudo de carácter ritual. Así sucedía entre algunas de las comunidades indígenas que habitaban los territorios selváticos del Nuevo Reino de Granada durante el siglo XVIII.

\footnotetext{
${ }^{35}$ AGN (Bogotá), Mejoras Materiales, t. 17, fol. 821v.

${ }^{36}$ Claude Lévi-Strauss, "The use of wild plants in tropical South America", en Handbook of South American Indians, vol. 6, Physical Anthropology, Linguistics and Cultural Geography of South American Indians, ed. Julian H. Steward (Washington: Smithsonian Institute-Bureau of American Ethnology, 1950), 465-486.

${ }^{37}$ Ibídem, 465-469.

${ }^{38}$ Claude Lévi-Strauss, El pensamiento salvaje (1964; reimpresión, México: Fondo de Cultura Económica, 1997), 11-59. Para el estudio etnográfico de un caso particular, véase Philippe Descola, La selva culta. Simbolismo y praxis en la ecología de los achuar (1986; reimpresión, Quito: MLAL; Abya-Yala, 1989).
} 
Uno de los casos más característicos de la época es el de los indígenas que habitaban las selvas de la provincia del Darién. Tales comunidades habían presentado una fuerte resistencia a la invasión europea y solo a fines del siglo XVII algunos indígenas estaban bajo influencia del gobierno colonial. Sin embargo, debido a la presencia de extranjeros en el área, especialmente franceses e ingleses interesados en el comercio de contrabando, y a un levantamiento liderado por el "indio mestizo" Luis García entre 1726 y $1727^{39}$, las relaciones con las autoridades políticas, militares y eclesiásticas fueron de gran hostilidad durante el siglo XVIII. En el gobierno del Virrey Eslava, primero de la segunda erección del virreinato, se trató de conciliar misionalmente con ellos, pero nada se logró, por lo que en tiempos del Virrey Messía de la Zerda se consideró que el trato suave era una pérdida de tiempo ${ }^{40}$. De ahí en adelante, y como la resistencia indígena tocaba puntos neurálgicos de la vida virreinal, como lo eran el comercio y los abastecimientos, al igual que se incrementaban los ataques furtivos a tropas $\mathrm{y}$ poblados españoles, la actitud de las autoridades giró completamente hacia una política de derrocamiento militar y exterminio. Sin ambages, el Virrey Guirior manifestaba que una eventual apertura del río Atrato, cerrado a todo tipo de navegación, facilitaría no solo el comercio sino también:

La reducción de los indios Cunas y sucesivamente los de la Provincia del Darién hasta limpiar todo el Istmo y descubrir nuevos senderos y caminos para el recíproco comercio y descubrimiento de minas y labor de muchas que son conocidas y reputadas por ricas ${ }^{41}$.

Poco más de una década después, Caballero y Góngora, quien tenía una visión particular del Darién y remontaba los orígenes históricos de su turbulenta situación a los tiempos de Pedrarias Dávila, informó que las comunidades indígenas del área habían sido reducidas a la sujeción a través de un pacto, el cual había sido violado

\footnotetext{
${ }^{39}$ Biblioteca Nacional de Colombia -en adelante BNC-(Bogotá), Fondo Antiguo, RM 160, pza. 1, fols. 2r-2v. El original del documento citado, en realidad una serie de varios documentos y mapas escritos y elaborados por el gobernador Andrés de Ariza en la década de 1770, reposa en el Archivo General de Indias, en Sevilla. Una trascripción del mismo se publicó recientemente, pero los compiladores al parecer desconocen la existencia de la copia de la BNC (Bogotá), que les hubiera permitido un trabajo comparativo y, por ende, crítico, sobre todo para llenar algunos vacíos y enmendar algunos errores de trascripción. Álvaro Baquero Montoya y Antonio Vidal Ortega, comps., La gobernación del Darién a finales del siglo XVIII. El informe de un funcionario ilustrado (Barranquilla: Uninorte, 2004).

40 "Defensa del gobierno del virrey Eslava, hecha por el oidor Eslava [1751]" [sic por Verástegui], en Colmenares, Relaciones e informes, 1: 56-57; "Relación del estado del Virreinato de Santafé, que hace el Exmo. Sr. D. Pedro Messía de la Zerda [...] [1772]", ibídem, 1: 146.

41 "Instrucción que deja a su sucesor en el mando el virrey D. Manuel Guirior [1776]", ibídem, 1: 288. Énfasis agregado.
} 
con un fallido asalto al fuerte de Carolina. Entonces, el arzobispo-virrey decidió arrancar de nuevo con el exterminio., por lo que puso en marcha un "plan de hostilidades" con el que:

Les quemaron muchos de sus pueblos, se mataron sus animales, se arrasaron sus plataneras, se aprisionaron bastantes de ellos mismos hasta que los redujimos a la última angustia ${ }^{42}$.

Después de tenerlos en tal estado se puso en marcha un plan de colonización con los mismos extranjeros que solían tener tratos con los indígenas, sugerido por Antonio Narváez, que no dio los resultados esperados pues las proyectadas colonias sufrieron en lo tocante a abastos y salud, mientras que los indígenas lograron continuar su resistencia.

En esta campaña violenta contra los pobladores indígenas del Darién, Andrés de Ariza, nombrado gobernador por el Virrey Guirior, trató de modificar algunos rasgos de la vida material de los indígenas sometidos, despreciando sus propias costumbres $^{43}$. Sin embargo, Ariza logró identificar y reconocer por escrito la vigorosidad de las relaciones propias que los hombres de esas selvas habían forjado con su entorno. Precisamente, hay que señalar aquí que Ariza identificó la riqueza de las "monterías" o cacerías y destacó que tales funciones conllevaban ritualidades específicas. La cacería, en efecto, debía ser producto de un acuerdo social y una disposición general que se preparaba con diez o quince días de anticipación. La empresa propiamente dicha era dirigida por el cacique, pero la compañía del "lere" o sacerdote era indispensable, y quien saliera a cazar por su propia cuenta no era reputado por buen miembro de la comunidad ${ }^{44}$. Así, más que un acto común, la cacería era un evento especial marcado por ritualidades específicas, lo cual se puede deducir también del hecho de que entre los bastimentos de las expediciones se contaba la chicha de maíz. Tales actividades proporcionaban el sustento alimenticio de origen animal que consistía en jabalíes, pavones, monos e iguanas, y en ellas se recurría a hachas y machetes, arpones, flechas y escopetas. Las armas de fuego y las herramientas metálicas habían sido asimiladas por estas culturas debido a la continuidad de los contactos con los europeos no españoles. En lo que toca a las armas de fuego, además, su posesión y uso había llegado a ser clave dentro de la vida cultural, ya que quien no tuviese escopeta era considerado de poca importancia ${ }^{45}$. Pero los propios usos técnicos de los indígenas del Darién también eran claves en las jornadas cinegéticas, por

\footnotetext{
42 "Relación del estado del Nuevo Reino de Granada, que hace el arzobispo obispo de Córdoba a su sucesor el excelentísimo señor don Francisco Gil y Lemos [1789]", ibídem, 1: 435, 459, 465.

${ }^{43}$ BNC (Bogotá), Fondo Antiguo, RM 160, pza. 1, fol. 18v.

${ }^{44}$ Ibídem, fols. 30r-30v, 32r.

${ }^{45}$ Ibídem, fols. 32v -33v.
} 
ejemplo en lo que tenía que ver con la movilización a través de los ríos y la morada en la selva, asuntos que en este caso se habían resuelto con un mismo artilugio: unas "piragüitas" que servían tanto para la navegación como para improvisar un rancho en las noches.

En la región selvática oriental del virreinato del Nuevo Reino de Granada, en la cuenca del gran río Orinoco y sus tributarios, habitaban múltiples comunidades indígenas sobre cuyas técnicas de cacería también han quedado testimonios, siendo el más importante el del jesuita Joseph Gumilla. En la obra de Gumilla todos los indígenas se miden con un mismo rasero, en el que la barbarie, la monstruosidad y la pereza son elementos comunes ${ }^{46}$. Pero lo que interesa destacar es la variedad y minuciosidad de las técnicas cinegéticas, que bien describe Gumilla, no obstante su apreciación de los indígenas. La cacería en las selvas del Orinoco tenía como factor fundamental la construcción de una ranchería al lado de un cauce, actividad en la que era necesario cortar la maleza, acumular leña y colgar los chinchorros o hamacas para dormir. En esa misma estación de ingreso y regreso se instalaba también el "cañizo" sobre el que posteriormente se secaba lentamente la carne obtenida $^{47}$. El ingreso a la selva, en la que generalmente se cazaban jabalíes, implicaba además la orientación certera, lo cual se lograba creando sutiles indicadores de rutas, especialmente cuando se perseguían las eufóricas piaras, momentos en los que los indígenas:

[...] van al mismo tiempo rompiendo ramas tiernas con gran destreza, las cuales sirven de seña segura para volver por los mismos pasos que habían ido. Y este modo de caminar dejando dichas señas, se practica en todos los viajes, $[\ldots]$ y la razón es, porque no hay caminos, ni trochas abiertas, y rarísima vez se forma senda: y así para seguir uno de aquellos derroteros, no se atiende al suelo, porque en él no hay señal, por estar cubierto de más de un palmo de hojas secas: sólo se atiende a las ramas quebradas, y por ellas conocen los indios cuántos años ha que no se trajinó aquel rumbo; porque la rama quebrada, cada año echa su renuevo, y por los mismos cuentan seguramente los años ${ }^{48}$.

Las técnicas de orientación de los indígenas debían llamar singularmente la atención del hombre de tradición hispánica, pues, como ya se indicó, su incursión en los espacios forestales, cuando pretendía ser certera y duradera, no se fiaba en ningún caso de leves indicaciones o marcas. No es extraño, pues, que Gumilla

${ }^{46}$ Gumilla, El Orinoco ilustrado, 78-79. Énfasis en el original.

${ }^{47}$ Cañizo es la expresión castiza utilizada por Gumilla; en este caso, es algo similar a las famosas barbacoas. Según el Diccionario de la Lengua castellana [1729], vol. 1, t. 2:131, es parecido a una estera, pues se conforma de cañas de igual tamaño atadas entre sí, artilugio que tenía varios usos en la España peninsular.

${ }^{48}$ Gumilla, El Orinoco ilustrado, 172. 
llame la atención sobre la ausencia de caminos, trochas o sendas, las formas culturales drásticas y más insolentes, por decirlo de algún modo, que le eran conocidas y que, probablemente, le darían más confianza. Asimismo, estas diferencias técnicas implicaban una diferencia de hábitos corporales cuando se caminaba por la selva, como es evidente en la cita anterior. Aquellos hombres que recorrían los caminos coloniales que cruzaban los montes debían fijar su mirada en las huellas erosivas dejadas sobre el terreno; los indios del Orinoco, en cambio, no necesitaban bajar sus cabezas, pues era su mirada al frente la que los orientaba, buscando minúsculas señales que, para otros, pasaban desapercibidas.

Las "monterías" de estas comunidades, finalmente, concluían tras quince o veinte días con grandes banquetes de chicha y carne que se extendían por dos o tres días, y después de los cuales se agotaban las viandas casi en su totalidad, finalizando un ciclo económico, técnico y ritual en el que los observadores externos difícilmente encontraban una lógica coherente.

\section{Secularización y utilidad: montes, selvas e Ilustración}

El religioso se adelantó con sus observaciones, valoraciones y propuestas a los gobernantes y hombres ilustrados del Nuevo Reino de Granada. Gumilla, en efecto, llamaba la atención sobre las inmensas utilidades que los indígenas sacaban de la selva y sus especies y manifestaba que los hombres blancos, hasta ese entonces, habían descubierto muy poco "en comparación del gran tesoro que yace escondido por falta de personas inteligentes". Resinas, aromas, frutas, raíces medicinales, bálsamos, aceites y multitud de especies fluviales lo hacían pensar en las utilidades que podía alcanzar en aquellos paraísos de la abundancia ${ }^{49}$. En este sentido, Gumilla se alejaba de la tradición europea que había concebido la naturaleza americana como inferior y débil desde la época de los primeros cronistas y que se consolidó durante el Siglo de las Luces ${ }^{50}$. Pero la década de los cuarenta del siglo XVIII no era aún el tiempo propicio para que los eventuales lectores de su obra en el joven virreinato la hallaran muy pertinente. En realidad, fue a partir de la década de 1770, y después de 1790 con un énfasis distinto, que las autoridades virreinales y los estudiosos ilustrados lograron expresar -desde el punto de vista de nuevas doctrinas económicas, usando una retórica particular y como parte de un ideario más amplio de reformas- una serie de nuevas valoraciones y propuestas frente a la naturaleza y sus recursos ${ }^{51}$. Este giro en la percepción, igualmente, hacía parte del

\footnotetext{
${ }^{49}$ Ibídem, 178-199.

50 Antonello Gerbi, La naturaleza de las Indias Nuevas. De Cristóbal Colón a Gonzalo Fernández de Oviedo (1975; reimpresión, México: Fondo de Cultura Económica, 1992).

51 Renán Silva, Los ilustrados de Nueva Granada, 1760-1808. Genealogía de una comunidad de interpretación (Medellín: Banco de la República; Universidad Eafit, 2002), 399-408.
} 
amplio debate sobre la naturaleza americana, pues durante el siglo XVIII, como se mencionó, se consolidaron en Europa las ideas sobre el Nuevo Mundo como una realidad natural inferior, inmadura y degenerada. Para los hombres americanos que adoptaron la perspectiva de la Ilustración fue fundamental debatir tales tesis y resaltar la exuberancia y fecundidad de la naturaleza que los rodeaba ${ }^{52}$. En medio de ese contexto, sobre todo en la última década del siglo y hasta 1808, fue que posibilidades como las que había señalado Gumilla comenzaron a destacarse para otras regiones del virreinato.

Igualmente, muchas tradiciones y creencias que rodeaban al mundo natural y a los hombres en su relación con este se tildaron de "supersticiones" o prejuicios y fueron consideradas obstáculos que era necesario erradicar para dar vía libre a la "nueva representación" de la naturaleza en la que esta aparecía no como "un objeto terrible que atemorice a los hombres", sino como una dádiva divina destinada para la felicidad terrenal y que podía ser objeto de reflexión racional ${ }^{53}$. Ahora bien, las ideas tradicionales con respecto a la naturaleza eran propias y características del mundo preindustrial y tenían sus raíces en tradiciones centenarias, en ocasiones milenarias, como ya se ha indicado para algunos casos específicos en este artículo. Las reformas de finales del siglo XVIII buscaron trastocar un componente primordial del mundo preindustrial consistente en que casi todos los aspectos materiales de la vida contenían en sí especiales significados espirituales y rituales, por lo que la naturaleza, por ejemplo, más que comprensión requería aplacamiento $^{54}$. Tales nociones, además, no eran exclusividad de los sectores rurales y "populares", pues tenían presencia entre casi toda la gente, en especial por estar particularmente ligadas al cristianismo y a sus distintas apropiaciones e interpretaciones. A decir verdad, los ilustrados no solo pretendían secularizar la percepción del entorno, sino también conciliar su visión racionalista del mundo con su profunda religiosidad católica, ya que concebían la existencia de una armonía entre el mundo natural y el revelado, lo cual se conoce como la doctrina del jusnaturalismo ${ }^{55}$.

\footnotetext{
52 Antonello Gerbi, La disputa del Nuevo Mundo. Historia de una polémica, 1750-1900 (1955; reimpresión, México: Fondo de Cultura Económica, 1982), 228-234.

${ }^{53}$ Silva, Los ilustrados, 420, 473; Renán Silva, Prensa y revolución a finales del siglo XVIII. Contribución a un análisis de la formación de la ideología de Independencia nacional (1988; reimpresión, Medellín: La Carreta, 2004), 123-126; Elías Trabulse, Ciencia y tecnología en el Nuevo Mundo (1994; reimpresión, México: Fondo de Cultura Económica, 1996), 78-115.

${ }^{54}$ Norman Pounds, La vida cotidiana: historia de la cultura material (1989; reimpresión, Barcelona: Crítica, 1992), 13-22.

55 Antonio Mestre, "La actitud religiosa de los católicos ilustrados", en El reformismo borbónico. Una visión interdisciplinar, ed. Agustín Guimerá (Madrid: Alianza; Centro Superior de Investigaciones Científicas; Mapfre), 152.
} 
Si bien los ilustrados insistieron en la secularización de las tradiciones culturales con respecto a la naturaleza, algunos se propusieron sobre todo generar valoraciones y pautas técnicas productivas que permitieran explotarla en función de su utilidad para la sociedad. José Celestino Mutis, desde inicios de la década de 1760, había realizado ya tal proposición haciendo énfasis en el papel de la ciencia y el aprovechamiento racional de los recursos; sus seguidores o discípulos, por su parte, recogieron tal propuesta pero la modificaron, de manera que a fines del siglo XVIII y comienzos del XIX el conocimiento científico quedó relegado a un medio más que a un fin, pues se radicalizó la perspectiva de la utilidad a raíz del descubrimiento de la "economía política", que ponía de presente la posibilidad de lograr el florecimiento económico y la prosperidad general a partir de explotaciones agrícolas que permitieran una conexión con el comercio ${ }^{56}$. En el Semanario del Nuevo Reino de Granada, Francisco José de Caldas, por ejemplo, manifestó que una actividad como la observación de los astros no pasaría de ser algo estéril si no se aplicaba al mejoramiento de los caminos y el beneficio del comercio, mientras que Francisco Antonio Zea, desde Europa, criticó la falta de dinamismo y compromiso del proyecto de la Real Expedición Botánica. De hecho, el modelo de trabajo científico de Mutis fue interpelado a favor de un mayor dinamismo que implicara una experiencia de campo más comprometida, el reconocimiento de saberes locales y una mayor tendencia utilitaria ${ }^{57}$.

Para el caso del aprovechamiento con fines científicos y comerciales de los espacios selváticos, los hallazgos, propuestas y actividades de extracción tuvieron objetos concretos de acción. La quina ejemplifica, con mucho, otros casos similares pero que no generaron tanta atención, polémica e "ilusión" entre los funcionarios monárquicos, los ilustrados, los comerciantes y algunos campesinos. Igualmente, este caso muestra el contrapunteo entre una perspectiva ilustrada de gabinete y una perspectiva ilustrada utilitaria, dos vertientes de la experiencia ilustrada, la una concentrada en la República de las letras y la otra interesada en las utilidades prácticas de la ciencia para la República civil ${ }^{58}$.

En la Audiencia de Quito los beneficios de la quina eran conocidos antes de la época de la Ilustración y de hecho en la primera mitad del siglo XVII la cascarilla fue introducida en el Perú y en Europa en un proceso de apropiación que aun es objeto de debate $^{59}$. Lo que si es seguro es que la aceptación de esta planta entre los

\footnotetext{
${ }^{56}$ Silva, Los ilustrados, 463-470.

${ }^{57}$ Antonio Lafuente, José de la Sota y Jaime Vilchis, "Dinámica imperial de la ciencia: los contextos metropolitano y colonial en la cultura española del siglo XVIII", en Guimerá, El reformismo, 189-194.

${ }^{58}$ Ibídem, 193.

59 Fernando I. Ortiz Crespo, La corteza del árbol sin nombre. Hacia una historia congruente del descubrimiento y difusión de la quina (Quito: Fundación Fernando Ortiz Crespo, 2002).
} 
naturalistas y médicos del Viejo Mundo fue bastante difícil en aquella época, puesto que hubo envíos adulterados y debido a que su difusión fue impulsada por los jesuitas, de manera que los protestantes se opusieron tenazmente a su utilización. Igualmente, la quina fue motivo de intensificación del debate entre los galenistas tradicionales y los médicos experimentales. Desde las décadas de 1730 y 1740, sin embargo, los científicos de la Misión Geodésica y otros naturalistas, como Miguel de Santisteban, se interesaron profundamente por la planta tras haberla conocido a su paso por Loja y generaron una particular ola de interés al respecto entre ilustrados naturalistas y entre funcionarios reales. Ellos escribieron sobre sus características y uso en un proceso en el cual se apropiaron del conocimiento nativo, además que con su aproximación racionalista oscurecieron la contribución del saber popular al respecto ${ }^{60}$.

En lo tocante a las autoridades superiores del virreinato, que ante todo representaban una perspectiva utilitaria, fue el Virrey Messía de la Zerda quien, al parecer, empezó a llamar la atención sobre las posibilidades comerciales de materiales no explotados hasta entonces, como maderas finas, aunque le asignaba todavía un papel central a la minería, posteriormente cuestionado ${ }^{61}$. Si bien es cierto que entre las esferas del gobierno ya circulaba la ilusión de aprovechar la quina debido a la actividad de los ilustrados no burócratas y al ejemplo de actividades extractivas como la de Loja ${ }^{62}$, fue el fiscal Moreno y Escandón (quien presentó una imagen bastante decadente del comercio en el virreinato) el burócrata de alto rango que llamó la atención sobre las posibilidades del "precioso febrífugo" que tenía mucho que prometer al adelantamiento del comercio ${ }^{63}$. Por su parte, el Virrey Guirior propuso que la explotación de quina se tomara por cuenta del Real Erario de manera que se aumentaran sus productos fiscales ${ }^{64}$. Fue en la década de 1780 cuando las autoridades metropolitanas, por la sugerencias de los burócratas del Nuevo Reino de Granada y la "campaña" de Mutis con respecto a la quina

\footnotetext{
${ }^{60}$ Eduardo Estrella, "Ciencia ilustrada y saber popular en el conocimiento de la quina en el siglo XVIII", en Saberes andinos. Ciencia y tecnología en Bolivia, Ecuador y Perú, ed. Marcos Cueto (Lima: Instituto de Estudios Peruanos, 1995), 37-57.

61 "Relación del estado del Virreinato de Santafé, que hace el Exmo. Sr. D. Pedro Messía de la Zerda [...]", ibídem, 139.

${ }^{62}$ María Soledad Castro Ponce, "La quina o cascarilla de los montes de Loja", en EcuadorEspaña. Historia y perspectiva. Estudios, coords. María Elena Porras y Pedro Calvo-Sotelo (Quito: Embajada de España en el Ecuador; Archivo Histórico del Ministerio de Relaciones Exteriores del Ecuador, 2001), 86-87.

63 "Estado del virreinato de Santafé, Nuevo Reino de Granada, [...] Por el D. D. Francisco Antonio Moreno y Escandón [...] [1772]", en Colmenares, Relaciones e informes, 1: 210211.

64 "Instrucción que deja a su sucesor en el mando el virrey D. Manuel Guirior [1776]", ibídem, 300-301.
} 
como parte de la Expedición Botánica ${ }^{65}$, ordenaron que se hiciesen remisiones a la corte y que se estancara tal producto, lo cual ya se había comentado en el virreinato y fue planteado posteriormente como algo muy necesario por el arzobispo-virrey ${ }^{66}$. Con todo, a fines del siglo XVIII aún no se había decidido al respecto y el Virrey José de Ezpeleta consideraba el estanco como algo perjudicial.

Además del debate utilitario se había emprendido también el debate letrado, pues cuando se descubrió la quina en los "montes septentrionales" del Nuevo Reino de Granada el hallazgo constituyó un interesante objeto para los hombres de ciencia. Fue Santisteban quien comentó a Mutis la existencia de árboles de cascarilla cerca de Santafé quien le regaló muestras con dibujos de la planta, aunque después se abriría un enfrenamiento sobre el descubrimiento ${ }^{67}$. Posteriormente, además, se consideró que las cualidades medicinales eran distintas y que la planta más potente y beneficiosa era exclusividad de la Audiencia de Quito. Pero después de aclarados el anterior punto y de introducir la quina en la esfera de las posibilidades comerciales, a raíz de su hallazgo en otras latitudes del virreinato, como la gobernación de Popayán, el antifebril se convirtió en una "especie emblemática" cuyo descubrimiento, estudio y explotación era considerado el principal aporte de los ilustrados del virreinato al bienestar del género humano, a la vez que era objeto generador de "ilusiones" y "utopías" sobre la prosperidad y riqueza que se podía alcanzar con su comercio. Llevado a lo particular, este fenómeno ha sido muy bien analizado por Renán Silva en el caso de la familia Torres de Popayán, especialmente de los hermanos Jerónimo y Camilo ${ }^{68}$.

La "fiebre" de la quina o cascarilla en la jurisdicción de la Audiencia de Santafé fue posterior a su decadencia en la jurisdicción de la Audiencia de Quito, donde se obtenía en Loja, Cuenca, Alausí y Chimbo, pero al parecer empezaba a escasear mientras que el debate entre exportadores y gobierno sobre el control de la extracción se hacía muy agudo, pues se pretendía hacerla un privilegio de la

\footnotetext{
${ }^{65}$ El empeño de Mutis por conocer las quinas del Nuevo Reino de Granada y difundir sus hallazgos al respecto se materializó particularmente en la publicación de su escrito "El arcano de la quina revelado al beneficio de la humanidad". Parte del largo texto apareció publicada por entregas. Papel periódico de la ciudad de Santafé de Bogotá (1791-1797; edición facsímil, Bogotá: Banco de la República, 1978) 3: num. 89-129.

66 "Relación del estado del Nuevo Reino de Granada, que hace el arzobispo obispo de Córdoba a su sucesor el excelentísimo señor don Francisco Gil y Lemos (1789)", ibídem, 428-429, 482-483.

${ }^{67}$ David J. Robinson, "Estudio preliminar", en Mil leguas por América. De Lima a Caracas 1740-1741. Diario de viaje de don Miguel de Santisteban (Bogotá: Banco de la República, 1992), 34-40.

${ }^{68}$ Silva, Los ilustrados, 422-433.
} 
Corona ${ }^{69}$. En efecto, don Manuel Daza, corregidor de Loja, informaba en 1766 que la falta de orden en la extracción de la especie silvestre estaba ocasionando la extinción de los árboles y que la comercialización de las cortezas se hacía mezclada con otras provenientes de árboles distintos, lo cual iba en contra del comercio y la salud. Igualmente, manifestaba que forasteros de otras latitudes ingresaban a Loja para intercambiar las cortezas con los indígenas dando en canje "ropas de las prohibidas", en contra de las ordenanzas reales, no solo económicas sino de dominación cultural ${ }^{70}$. Fue por ello que el corregidor promulgó una serie de ordenanzas en las que impelía la solicitud de su licencia para la explotación, reiteraba la calidad de "comunes" de los árboles y solicitaba que no todos los habitantes se dedicaran a su explotación, pues otras actividades igualmente importantes sufrían detrimento por falta de mano de obra ${ }^{71}$. Las ordenanzas fueron desobedecidas aun por miembros del cabildo involucrados en explotaciones de "cerros prohibidos".

En la jurisdicción de Santafé también se debatió el tema de la explotación de la quina y su propagación. Ante todo, tras el celebrado descubrimiento y el comienzo de la "rapiña" no controlada, que fue muy general, las propuestas gubernamentales e ilustradas tendían a suplantar el caos con disciplina; disciplina y racionalidad en la identificación, la extracción y la propagación de las especies que brindaban los recursos $^{72}$. Así, el funcionario Sebastián Josef López Ruiz, comisionado en muchos asuntos de explotación de recursos naturales en la segunda mitad del siglo XVIII y que decía haberse familiarizado con la quina "aprendiendo en el monte su conocimiento", manifestaba en 1796 que la conservación y propagación de los preciados árboles se podía lograr implementando adecuadas técnicas de corte y replantando. López Ruiz, comprometido con la perspectiva utilitaria, escribía que:

${ }^{69}$ Philip Louis Astuto, Eugenio Espejo. Reformador ecuatoriano de la Ilustración (17471795) (México: Fondo de Cultura Económica, 1969), 106-109.

70 Por "ropas prohibidas" deben entenderse aquí los tejidos de algodón y de lienzo procedentes de "países extraños" que comenzaban a abundar en los dominios de España y que habían sido prohibidos en 1728, prohibición ratificada en 1771 para proteger las manufacturas peninsulares y americanas. Véase Arnold J. Bauer, Somos lo que compramos. Historia de la cultura material en América Latina (2001; reimpresión, México: Taurus, 2002), 153-155; Pragmática sanción de Su Majestad, en fuerza de ley, por la qual se prohíbe la introdución y uso en estos Reynos de los tegidos de algodón, ó con mezcla de él, de Fábrica estraña [...] (Madrid: Antonio Sanz, 1771). Una copia del impreso se puede localizar en AGN (Bogotá), Reales Cédulas y Órdenes, t. 19, fols. 31-36.

${ }_{71}^{71}$ AGN (Bogotá), Quinas, tomo único, núm. de orden 17, fols. 705r-707r.

72 Así sucedió en muchos casos europeos cuando se pretendió retornar a los espacios boscosos como recursos ecológicos y económicos. Schama, Landscape, 45-50. En una conferencia a la que tuve oportunidad de asistir, un investigador europeo de la Universidad de la Suiza italiana tocó temas similares desde una perspectiva comparada. Jon Mathieu, "Historia de Montaña: ¿Por qué? ¿Cómo?" (Conferencia presentada en el II Simposio Colombiano de Historia y Ambiente, Bogotá, septiembre 30 de 2004). 
No se debían hacer los acopios de las cortezas de quina indistintamente y a un mismo tiempo en todos los montes que la producen, sino más bien con una prudente y arreglada alternativa, sucediéndose unos a otros para proceder con orden, y economía en los bastos de un ramo tan precioso, como de primera absoluta necesidad para la conservación del género humano $[\ldots]^{73}$.

Igualmente, manifestaba que se debían cortar dejándolos en pie y con cobertura de corteza en el tronco hasta la altura de un hombre regular, para así lograr obtener otra cosecha en los siguientes ocho o doce años, mientras que la propagación debía fomentarse sembrando en los mismos montes de origen por el método de "estacadas" o esquejes.

Las advertencias del comisionado, quien se adjudicaba haber descubierto los recursos antifebriles en las "montañas" de Santafé y Santa Marta desde $1774^{74}$, reflejaban situaciones que ya habían generado denuncias, pues en 1792 Francisco Bianchi había asegurado que en jurisdicción de Fusagasugá el desorden de los acopios estaba generando la destrucción total de los recursos en los montes cercanos y la mala fama del producto:

Su aniquilación y descrédito posterior ha consistido, en que varios sujetos, ahora y anteriormente, tanto vecinos de este pueblo, como de la capital, y de otras partes, sin superior licencia de Vuestra Excelencia los más; o con ella muy pocos; pero casi todos sin inteligencia alguna, se han determinado a mandar extraer enormes porciones de varias especies de quina: encargan sus cortes a los jornaleros o cosecheros de ella, torpes, y desidiosos, que faltos por otra parte de los necesarios conocimientos e industria, internan los montes desiertos, donde nacen estos árboles, los talan, los derriban inconsideradamente y los desolan sin discreción, ni método: de aquí se sigue su destrucción, su total ruina, y la escasez de ellos, que ya se advierte en todos estos contornos, y lo confiesan los mismo cosecheros, que caminan en el día mucho para encontrarlos ${ }^{75}$.

En el mismo manuscrito se hace referencia a los constantes problemas de propiedad y derechos de explotación que se generaban en los montes donde se hallaban los preciados árboles, lo que incluía la intervención no siempre justa de las autoridades, el acaparamiento de tierras y la exigencia de pagos por

${ }^{73}$ BNC (Bogotá), Fondo Antiguo, RM 162, pza. 8, fol. 106r.

${ }^{74}$ Ibídem, pza. 9, fols. 117r-138r. Mutis y López tuvieron un largo enfrentamiento, pues cada uno reclamaba el descubrimiento y fomento de la quina en la Audiencia de Santafé. La noticia de la planta, como ya se dijo, la obtuvo Mutis de Miguel de Santisteban.

${ }^{75}$ AGN (Bogotá), Quinas, tomo único, núm. de orden 6, fol. 139v. 
explotación, aunque es posible que Bianchi estuviera exagerando el problema buscando una suerte de monopolio, existía un sustento verídico de la situación.

A inicios del siglo XIX la orgía extractiva estaba en su máximo nivel en tiempos coloniales, y todavía estaba por llegar el ciclo extractivo de la segunda mitad de tal centuria. Así, durante los últimos años del virreinato, antes de que llegara la crisis política de 1808, se multiplicaron los conflictos de los que había hablado el testigo antes citado. En Ibagué, por ejemplo, en 1804, la aventura extractiva de Ignacio de Buenaventura y Luis Caicedo, presentada como proyecto de "salvación familiar", se vio interrumpida por Miguel Carvajal, un vecino que alegaba que aquellos hombres estaban sacando recursos de sus tierras y que no quería recibir ninguna contribución o pago de arrendamiento para permitir la "saca" de las cortezas ${ }^{76}$.

Otro conflicto se presentó en Ambalema, en donde Don Antonio Gago solicitó autorización para explotar quinas de buena calidad entre las quebradas de San Juan y los Piñones, tierras realengas que caían en la jurisdicción de Mariquita. La autorización fue concedida y Gago se internó con peones en tal selva, conocida como montañas de Coloya y en las montañas del páramo del Ruiz. En aquellos parajes había construido caminos y un rancho, y había asegurado la presencia de herramientas y barbacoas para secar la quina, lo cual constituía el mundo técnico básico de la extracción de la corteza. Pero a pesar de su autorización, el alcalde de Mariquita, don Pedro Pérez de la Valleja, le prohibió tal actividad alegando tener licencia del corregidor para explotar los mismos montes ${ }^{77}$. El alcalde de Mariquita argumentaba que él había descubierto las quinas desde 1804 y que tras contarle a Gago, este había enviado peones y comenzado a explotar la zona más promisoria ${ }^{78}$.

En el caso anterior, era la ventaja del primer descubrimiento y el consiguiente derecho de extracción el elemento que estaba en el centro del debate. Ahora bien, tal tipo de problemáticas se daban entre los explotadores, mientras que entre los explotadores y comerciantes se libraban otros debates con el gobierno virreinal. El más delicado tenía que ver con un gran obstáculo para exportar la quina: las licencias de comercio que legitimaban las transacciones, y el pago de "derechos de salida" " En efecto, la libre exportación fue en esta época una ilusión esporádica, dificultada además por las guerras del contexto imperial, precisamente, en la época de vigencia del Reglamento de Libre Comercio, entre 1784 y 1793. De esta manera, la quina fue protagonista de los grandes debates que caracterizaron la época de las reformas borbónicas y el Iluminismo.

\footnotetext{
${ }^{76}$ Ibídem, núm. de orden 4, fols. 121r-122r.

${ }^{77}$ Ibídem, núm. de orden 22 , fols. 745 r, 762r.

${ }^{78}$ Ibídem, fols. $764 \mathrm{r}, 765 \mathrm{v}$.

${ }^{79}$ Silva, Los ilustrados, 432.
} 
Finalmente, es necesario resaltar que en la segunda mitad del siglo XVIII los montes y las selvas del virreinato fueron espacios revalorizados desde un ideario que englobaba su desmitificación y secularización, su cocimiento científico y su explotación técnica racional, movimiento intelectual, económico y cultural que a grandes rasgos identifica el mundo occidental de la época, pero que en cada caso presenta elementos particulares importantes y que representaba no solo una serie de rupturas culturales y de innovaciones económicas, sino la esperanza, personal o colectiva, de un mundo mejor y de una vida más próspera y feliz.

\section{Bibliografía}

\section{Fuentes primarias}

Archivo General de la Nación, Bogotá, Colombia.

Archivo Histórico de Antioquia, Medellín, Colombia.

Biblioteca Nacional de Colombia, Bogotá, Colombia.

Diccionario de la Lengua castellana en el que se explica el verdadero sentido de las voces, su naturaleza y calidad, con las phrases o modos de hablar, los proverbios o refranes, y otras cosas convenientes al uso de la lengua, $3 \mathrm{t}$. Madrid: Real Academia Española, 1726-1739; edición facsímil bajo el título Diccionario de Autoridades, Madrid: Gredos, 2002.

Oviedo, Basilio Vicente de. Cualidades y riquezas del Nuevo Reino de Granada. Bogotá: Biblioteca de Historia Nacional, 1930.

Papel periódico de la ciudad de Santafé de Bogotá. 3 t. 1791-1797; edición facsímil, Bogotá: Banco de la República, 1978.

\section{Fuentes secundarias}

Arnold, David. La naturaleza como problema histórico. El medio, la cultura y la expansión de Europa. 1996; reimpresión, México: Fondo de Cultura Económica, 2001.

Astuto, Philip Louis. Eugenio Espejo. Reformador ecuatoriano de la Ilustración (1747-1795). México: Fondo de Cultura Económica, 1969.

Bauer, Arnold J. Somos lo que compramos. Historia de la cultura material en América Latina. 2001; reimpresión, México: Taurus, 2002. 
Baquero Montoya, Álvaro y Antonio Vidal Ortega, comps. La gobernación del Darién a finales del siglo XVIII. El informe de un funcionario ilustrado. Barranquilla: Uninorte, 2004.

Bowler, Peter J. Historia Fontana de las Ciencias Ambientales. 1992; reimpresión, México: Fondo de Cultura Económica, 1998.

Brading, David A. Orbe indiano. De la monarquía católica a la república criolla, 1492-1867. 1991; reimpresión, México: Fondo de Cultura Económica, 2003.

Braudel, Fernand. Civilización material, economía y capitalismo, siglos XV-XVIII. T. 1. Las estructuras de lo cotidiano: lo posible y lo imposible. 1967; reimpresión, Madrid: Alianza, 1984.

Castro Herrera, Guillermo. "Naturaleza, sociedad e historia en América Latina". En Ecología política. Naturaleza, sociedad y utopía, comp. Héctor Alimonda, 83-99. Buenos Aires: Consejo Latino Americano de Ciencias Sociales, 2002.

Castro Ponce, María Soledad. "La quina o cascarilla de los montes de Loja". En Ecuador-España. Historia y perspectiva. Estudios, coords. María Elena Porras y Pedro Calvo-Sotelo. Quito: Embajada de España en el Ecuador; Archivo Histórico del Ministerio de Relaciones Exteriores del Ecuador, 2001.

Colmenares, Germán. Relaciones e informes de los gobernantes de la Nueva Granada. 3 t. Bogotá: Biblioteca Banco Popular, 1989.

Córdoba Ochoa, Luis Miguel. De la quietud a la felicidad. La villa de Medellín y los procuradores del cabildo entre 1675 y 1785 . Bogotá: Instituto Colombiano de Cultura Hispánica, 1998.

Crosby, Alfred W. Imperialismo ecológico. La expansión biológica de Europa, 900-1900. 1986; reimpresión, Barcelona: Crítica, 1999.

Descola, Philippe. La selva culta. Simbolismo y praxis en la ecología de los achuar. 1986; reimpresión, Quito: MLAL; Abya-Yala, 1989.

Elias, Norbert. "Compromiso y distanciamiento" [1956-1977/1978]. En Compromiso y distanciamiento. Ensayos de sociología del conocimiento. Barcelona: Península, 1990. 
Estrella, Eduardo. "Ciencia ilustrada y saber popular en el conocimiento de la quina en el siglo XVIII". En Saberes andinos. Ciencia y tecnología en Bolivia, Ecuador y Perú, ed. Marcos Cueto, 37-57. Lima: Instituto de Estudios Peruanos, 1995.

Fernández-Armesto, Felipe. Civilizaciones. La lucha del hombre por controlar la naturaleza. 2000; reimpresión, Madrid: Taurus, 2002.

Gerbi, Antonello. La disputa del Nuevo Mundo. Historia de una polémica, 17501900. 1955; reimpresión, México: Fondo de Cultura Económica, 1982.

La naturaleza de las Indias Nuevas. De Cristóbal Colón a Gonzalo Fernández de Oviedo. 1975; reimpresión, México: Fondo de Cultura Económica, 1992.

Gumilla, Joseph. El Orinoco ilustrado. Historia natural, civil, y geográfica de este gran rio. 1741; reimpresión, Bogotá: ABC, 1955.

Herrera Ángel, Marta. Ordenar para controlar. Ordenamiento espacial y control político en las llanuras del Caribe y en los Andes centrales neogranadinos. Siglo XVIII. Bogotá: Academia Colombiana de Historia; Instituto Colombiano de Antropología e Historia, 2002.

Jiménez Meneses, Orián, Edgardo Pérez Morales y Felipe Gutiérrez Flórez, eds. Caminos, rutas y técnicas: huellas espaciales y estructuras sociales en Antioquia. Medellín: Universidad Nacional de Colombia, 2005.

Lafuente, Antonio, José de la Sota y Jaime Vilchis. "Dinámica imperial de la ciencia: los contextos metropolitano y colonial en la cultura española del siglo XVIII". En El reformismo borbónico. Una visión interdisciplinar, ed. Agustín Guimerá, 175-202. Madrid: Alianza; Consejo Superior de Investigaciones Científicas; Mapfre, 1996.

Le Goff, Jacques. "El desierto y el bosque en el Occidente medieval". En Lo maravilloso y lo cotidiano en el Occidente medieval. Barcelona: Gedisa, 1986.

Lévi-Strauss, Claude. "The Use of Wild Plants in Tropical South America". En Handbook of South American Indians. Vol. 6. Physical Anthropology, Linguistics and Cultural Geography of South American Indians, ed. Julian H. Steward, 465-486. Washington: Smithsonian Institute-Bureau of American Ethnology, 1950. 
El pensamiento salvaje. 1964; reimpresión, México: Fondo de Cultura Económica, 1997.

Mathieu, Jon. "Historia de montaña: ¿Por qué? ¿Cómo?”. Conferencia presentada en el III simposio Colombiano de Historia y Ambiente. Bogotá, septiembre 30 de 2004.

Meléndez Dobles, Silvia. "La historia ambiental: aportes interdisciplinarios y balance crítico desde América Latina". Cuadernos digitales (Costa Rica), 7, núm. 19 (2002). Revista en línea. Costa Rica: Universidad de Costa Rica, 2002. Obtenido de la red mundial el 6 de septiembre de 2006, 12:30 horas. http://historia.fcs.ucr.ac.cr/cuadernos/c19-his.pdf.

Mestre, Antonio. "La actitud religiosa de los católicos ilustrados". En El reformismo borbónico. Una visión interdisciplinar, ed Agustín Guimerá. Madrid: Alianza; Consejo Superior de Investigaciones Científicas; Mapfre, 1996.

Ortiz Crespo, Fernando I. La corteza del árbol sin nombre. Hacia una historia congruente del descubrimiento y difusión de la quina. Quito: Fundación Fernando Ortiz Crespo, 2002.

Pounds, Norman. La vida cotidiana: historia de la cultura material. 1989; reimpresión, Barcelona: Crítica, 1992.

Robinson, David J. "Estudio preliminar". En Mil leguas por América. De Lima a Caracas 1740-1741. Diario de viaje de don Miguel de Santisteban. Bogotá: Banco de la República, 1992.

Schama, Simon. Landscape and Memory. 1995; reimpresión, Nueva York: Vintage Books, 1996.

Silva, Renán. Los ilustrados de Nueva Granada, 1760-1808. Genealogía de una comunidad de interpretación. Medellín: Banco de la República; Universidad Eafit, 2002.

Prensa y revolución a finales del siglo XVIII. Contribución a un análisis de la formación de la ideología de Independencia nacional. 1988; reimpresión, Medellín: La Carreta, 2004.

Trabulse, Elías. Ciencia y tecnología en el Nuevo Mundo. 1994; reimpresión, México: Fondo de Cultura Económica, 1996. 
Fecha de recepción: 22 de febrero de 2006.

Fecha de aprobación: 14 de junio de 2006. 